\title{
Fixed Points for Contractive Mappings of Integral Type Involving $\omega$-Distance and Applications
}

\author{
Haiyan Gao, ${ }^{1,2} \mathrm{Na} \mathrm{Liu}^{3}$ and Liangshi Zhao $\mathbb{D}^{4}$ \\ ${ }^{1}$ School of Mathematics, Dongbei University of Finance and Economics, Dalian, Liaoning 116025, China \\ ${ }^{2}$ School of Management, Dalian University of Finance and Economics, Dalian, Liaoning 116600, China \\ ${ }^{3}$ Department of Mathematics, Liaoning Normal University, Dalian, Liaoning 116029, China \\ ${ }^{4}$ Center for Studies of Marine Economy and Sustainable Development, Liaoning Normal University, Dalian, Liaoning 116029, China
}

Correspondence should be addressed to Liangshi Zhao; liangshizhao85@163.com

Received 14 November 2020; Revised 14 December 2020; Accepted 11 January 2021; Published 23 January 2021

Academic Editor: Zoran Mitrovic

Copyright (c) 2021 Haiyan Gao et al. This is an open access article distributed under the Creative Commons Attribution License, which permits unrestricted use, distribution, and reproduction in any medium, provided the original work is properly cited.

In this paper, we use $\omega$-distance to prove the existence, uniqueness, and iterative approximations of fixed points for a few contractive mappings of integral type in complete metric spaces. The proved results are used to investigate the solvability of certain nonlinear integral equations. Four examples are given.

\section{Introduction}

The researchers [1-17] attained various generalizations of the well-known Banach contraction principle. In 2001, Rhoades [15] certified several fixed point results for the weakly contractive mappings. Branciari [1] introduced the notion of integral type contraction and established a nice fixed point result for the mapping. Many authors investigated the existence of fixed points for a lot of contractive mappings of integral type, for example, see [11-14]. Particularly, Liu et al. [14] obtained several fixed point theorems for contractive mappings of integral type in complete metric spaces.

Kada et al. [8] introduced the concept of $\omega$-distance in metric spaces and proved a few fixed point theorems for some contractive mappings by using $\omega$-distance. It is clear that the results in [8] extended the Caristi's fixed point theorem, Ekeland's $\varepsilon$-variational's principle, and the nonconvex minimization theorem. The researchers in $[3,5-7,9,10$, 17] got several fixed point results for certain contractive mappings with respect to $\omega$-distance.

In this paper, we prove the existence, uniqueness, and iterative approximations of fixed points for several kinds of mappings, which satisfy some contractive conditions of integral type with respect to $\omega$-distance in complete metric spaces. We also construct four illustrative examples and give applications of the obtained results in nonlinear Fredholm and Volterra integral equations, respectively. Our results generalize or differ from the corresponding fixed point theorems in $[1,14,15]$.

\section{Preliminaries}

Let $\mathbb{N}$ denotes the set of all positive integers, $R=(-\infty,+\infty)$, $R^{+}=[0,+\infty), N_{0}=N \cup\{0\}$ and

$$
\begin{gathered}
\Phi_{1}=\left\{w \mid w: R^{+} \rightarrow R^{+}\right. \text {is Lebesgue integrable, summable on each } \\
\text { compact subset of } \left.R^{+} \text {and } \int_{0}^{\varepsilon} w(r) d r>0 \text { for each } \varepsilon>0\right\} ; \\
\Phi_{2}=\left\{w \mid w \in \Phi_{1} \text { and satisfies that } \int_{0}^{u} w(r) d r<\int_{0}^{v} w(r) d r\right. \text { for each } \\
\left.u, v \in R^{+} \text {with } u<v\right\} ; \\
\Phi_{3}=\left\{w \mid w: R^{+} \rightarrow R^{+} \text {is nondecreasing, continuous, } w(0)\right. \\
\left.=0, \lim _{t \rightarrow+\infty} w(t)=+\infty \text { and } w(t)>0 \text { for each } t>0\right\}
\end{gathered}
$$




$$
\begin{aligned}
\Phi_{4} & =\left\{w \mid w: R^{+} \rightarrow R^{+} \text {is lower semi }- \text { continuous, } w(0)\right. \\
& =0 \text { and } w(t)>0 \text { for each } t>0\} .
\end{aligned}
$$

Recall that a self-mapping $f$ in a metric space $X$ is called orbitally continuous if $\lim _{n \rightarrow \infty} f^{n} x=u$ implies $\lim _{n \rightarrow \infty} f^{n+1} x$ $=f u$ for each $\left\{f^{n} x\right\}_{n \in N_{0}} \subseteq X$ and $u \in X$.

\section{Fixed Point Results with respect to $\omega$ -Distance}

In this section, using $\omega$-distance, we give four fixed point theorems for the contractive mappings (2), (38), (82), and (114) below.

Theorem 1. Let $p$ be a $\omega$-distance in a complete metric space $(X, d)$ and let $f: X \rightarrow X$ satisfy that

$$
\int_{0}^{p(f x, f y)} w(r) d r \leq \int_{0}^{p(x, y)} w(r) d r-\int_{0}^{\psi(p(x, y))} w(r) d r, \forall x, y \in X .
$$

Here, $(w, \psi) \in \Phi_{1} \times \Phi_{4}$. Then, $f$ possesses a unique fixed point $u \in X$ such that $p(u, u)=0$,

$$
\lim _{n \rightarrow \infty} p\left(f^{n} x_{0}, u\right)=0 \text { and } \lim _{n \rightarrow \infty} f^{n} x_{0}=u \text { for each } x_{0} \in X
$$

Proof. Firstly, we claim the existence of fixed points of $f$ in $X$. Put $x_{0} \in X$ and $x_{n}=f^{n} x_{0}$ for each $n \in N_{0}$. Now, we need to think over two situations as follows:

Case 2. $x_{n_{0}}=x_{n_{0}-1}$ for some $n_{0} \in N$. Clearly, $x_{n_{0}-1}$ is a fixed point of $f$ and $\lim _{n \rightarrow \infty} f^{n} x_{0}=x_{n_{0}-1}$. Suppose that $p\left(x_{n_{0}-1}\right.$, $\left.x_{n_{0}-1}\right)>0$. Making use of $(2)$ and $(w, \psi) \in \Phi_{1} \times \Phi_{4}$, we obtain that

$$
\begin{aligned}
\int_{0}^{p\left(x_{n_{0}-1}, x_{n_{0}-1}\right)} w(r) d r & =\int_{0}^{p\left(f x_{n_{0}-1}, f x_{n_{0}-1}\right)} w(r) d r \\
& \leq \int_{0}^{p\left(x_{n_{0}-1}, x_{n_{0}-1}\right)} w(r) d r \\
& -\int_{0}^{\psi\left(p\left(x_{n_{0}-1}, x_{n_{0}-1}\right)\right)} w(r) d r \\
& <\int_{0}^{p\left(x_{n_{0}-1}, x_{n_{0}-1}\right)} w(r) d r,
\end{aligned}
$$

which is ridiculous. Hence, $p\left(x_{n_{0}-1}, x_{n_{0}-1}\right)=0$, which means that

$$
\lim _{n \rightarrow \infty} p\left(f^{n} x_{0}, x_{n_{0}-1}\right)=p\left(x_{n_{0}-1}, x_{n_{0}-1}\right)=0 ;
$$

Case 3. $x_{n} \neq x_{n-1}$ for all $n \in N$. Suppose that

$$
p\left(x_{n_{0}-1}, x_{n_{0}}\right)=0 \text { for some } n_{0} \in N \text {. }
$$

(2), (6), and $(w, \psi) \in \Phi_{1} \times \Phi_{4}$ ensure that

$$
\begin{aligned}
0 & \leq \int_{0}^{p\left(x_{n_{0}}, x_{n_{0}+1}\right)} w(r) d r=\int_{0}^{p\left(f x_{n_{0}-1}, f x_{n_{0}}\right)} w(r) d r \\
& \leq \int_{0}^{p\left(x_{n_{0}-1}, x_{n_{0}}\right)} w(r) d r-\int_{0}^{\psi\left(p\left(x_{n_{0}-1}, x_{n_{0}}\right)\right)} w(r) d r=0,
\end{aligned}
$$

that is,

$$
\int_{0}^{p\left(x_{n_{0}}, x_{n_{0}+1}\right)} w(r) d r=0
$$

The above equation and $w \in \Phi_{1}$ give that

$$
p\left(x_{n_{0}}, x_{n_{0}+1}\right)=0 \text {. }
$$

Combining (6), (9), and $\left(p_{1}\right)$, we know that

$$
0 \leq p\left(x_{n_{0}-1}, x_{n_{0}+1}\right) \leq p\left(x_{n_{0}-1}, x_{n_{0}}\right)+p\left(x_{n_{0}}, x_{n_{0}+1}\right)=0,
$$

that is,

$$
p\left(x_{n_{0}-1}, x_{n_{0}+1}\right)=0
$$

Because of Lemma 1 in [8], (6), and (11), we deduce that $x_{n_{0}}=x_{n_{0}+1}$, which is contradictive, and, hence,

$$
p\left(x_{n-1}, x_{n}\right)>0, \forall n \in N \text {. }
$$

By means of $(w, \psi) \in \Phi_{1} \times \Phi_{4}$, (2) and (12), we have

$$
\begin{aligned}
\int_{0}^{p\left(x_{n}, x_{n+1}\right)} w(r) d r & =\int_{0}^{p\left(f x_{n-1}, f x_{n}\right)} w(r) d r \\
& \leq \int_{0}^{p\left(x_{n-1}, x_{n}\right)} w(r) d r-\int_{0}^{\psi\left(p\left(x_{n-1}, x_{n}\right)\right)} w(r) d r \\
& <\int_{0}^{p\left(x_{n-1}, x_{n}\right)} w(r) d r, \forall n \in N,
\end{aligned}
$$

which together with (12) and $w \in \Phi_{1}$ ensures that

$$
0<p\left(x_{n}, x_{n+1}\right)<p\left(x_{n-1}, x_{n}\right), \forall n \in N \text {. }
$$

We see from (14) that $\left\{p\left(x_{n}, x_{n+1}\right)\right\}_{n \in N_{0}}$ is a positive and strictly decreasing sequence. It follows that

$$
\lim _{n \rightarrow \infty} p\left(x_{n}, x_{n+1}\right)=c \text { for some } c \geq 0 \text {. }
$$

Now, we claim that $c=0$. Otherwise, $c>0$. In view of Lemma 2.1 in [12], (2), (15), and $(w, \psi) \in \Phi_{1} \times \Phi_{4}$, we see that 


$$
\begin{aligned}
\int_{0}^{c} w(r) d r & =\limsup _{n \rightarrow \infty} \int_{0}^{p\left(x_{n}, x_{n+1}\right)} w(r) d r \\
& =\limsup _{n \rightarrow \infty} \int_{0}^{p\left(f x_{n-1}, f x_{n}\right)} w(r) d r \\
& \leq \limsup _{n \rightarrow \infty}\left(\int_{0}^{p\left(x_{n-1}, x_{n}\right)} w(r) d r-\int_{0}^{\psi\left(p\left(x_{n-1}, x_{n}\right)\right)} w(r) d r\right) \\
& \leq \limsup _{n \rightarrow \infty} \int_{0}^{p\left(x_{n-1}, x_{n}\right)} w(r) d r \\
& -\liminf _{n \rightarrow \infty} \int_{0}^{\psi\left(p\left(x_{n-1}, x_{n}\right)\right)} w(r) d r \\
\leq & \int_{0}^{c} w(r) d r-\int_{0}^{\psi(c)} w(r) d r<\int_{0}^{c} w(r) d r .
\end{aligned}
$$

It is ridiculous. Therefore, $c=0$. Consequently,

$$
\lim _{n \rightarrow \infty} p\left(x_{n}, x_{n+1}\right)=0
$$

In the same way, we have

$$
\lim _{n \rightarrow \infty} p\left(x_{n+1}, x_{n}\right)=0
$$

Now, we proceed to show that

$$
\lim _{n, m \rightarrow \infty} p\left(x_{n}, x_{m}\right)=0
$$

Suppose that there exists a real number $\varepsilon>0$ such that for every $k \in N$, there exist $m(k), n(k) \in N$ satisfying

$$
p\left(x_{n(k)}, x_{m(k)}\right)>\varepsilon, m(k)>n(k)>k, \forall k \in N \text {. }
$$

For each $k \in N, m(k)$ denotes the least integer exceeding $n(k)$ and satisfying (20). Obviously,

$$
p\left(x_{n(k)}, x_{m(k)}\right)>\varepsilon \text { and } p\left(x_{n(k)}, x_{m(k)-1}\right) \leq \varepsilon, \forall k \in N \text {. }
$$

On account of $\left(p_{1}\right)$ and (21), we obtain that

$$
\begin{aligned}
\varepsilon< & p\left(x_{n(k)}, x_{m(k)}\right) \leq p\left(x_{n(k)}, x_{n(k)-1}\right) \\
& +p\left(x_{n(k)-1}, x_{m(k)-1}\right)+p\left(x_{m(k)-1}, x_{m(k)}\right) \\
\leq & p\left(x_{n(k)}, x_{n(k)-1}\right)+p\left(x_{n(k)-1}, x_{n(k)}\right) \\
& +p\left(x_{n(k)}, x_{m(k)-1}\right)+p\left(x_{m(k)-1}, x_{m(k)}\right) \\
\leq & p\left(x_{n(k)}, x_{n(\mathrm{k})-1}\right)+p\left(x_{n(k)-1}, x_{n(k)}\right) \\
& +\varepsilon+p\left(x_{m(k)-1}, x_{m(k)}\right), \forall k \in N .
\end{aligned}
$$

Letting $k$ tend to infinity in (22) and taking advantage of
(17), (18), and (21), we have

$$
\lim _{k \rightarrow \infty} p\left(x_{n(k)}, x_{m(k)}\right)=\lim _{k \rightarrow \infty} p\left(x_{n(k)-1}, x_{m(k)-1}\right)=\varepsilon .
$$

In light of Lemma 2.1 in [12], (2), (23), and $(w, \psi) \in \Phi_{1}$ $\times \Phi_{4}$, we deduct that

$$
\begin{aligned}
\int_{0}^{\varepsilon} w(r) d r & =\limsup _{k \rightarrow \infty} \int_{0}^{p\left(x_{n(k)}, x_{m(k)}\right)} w(r) d r \\
& =\limsup _{k \rightarrow \infty} \int_{0}^{p\left(f x_{n(k)-1}, f x_{m(k)-1}\right)} w(r) d r \\
& \leq \limsup _{k \rightarrow \infty}\left(\int_{0}^{p\left(x_{n(k)-1}, x_{m(k)-1}\right)} w(r) d r-\int_{0}^{\psi\left(p\left(x_{n(k)-1}, x_{m(k)-1}\right)\right)} w(r) d r\right) \\
& \leq \limsup _{k \rightarrow \infty} \int_{0}^{p\left(x_{n(k)-1}, x_{m(k)-1}\right)} w(r) d r-\liminf _{k \rightarrow \infty} \int_{0}^{\psi\left(p\left(x_{n(k)-1}, x_{m(k)-1}\right)\right)} w(r) d r \\
& \leq \int_{0}^{\varepsilon} w(r) d r-\int_{0}^{\psi(\varepsilon)} w(r) d r<\int_{0}^{\varepsilon} w(r) d r .
\end{aligned}
$$

It is ridiculous. Of course, (19) is true.

Assume that $\varepsilon>0$ and $\delta$ denotes the real number appearing in (3) of [8]. By means of (19), we infer that there is $N \in N$ satisfying

$$
p\left(x_{N}, x_{n}\right)<\delta, p\left(x_{N}, x_{m}\right)<\delta, \forall n, m>N
$$

which ensures that

$$
d\left(x_{n}, x_{m}\right) \leq \varepsilon, \forall n, m>N
$$

So $\left\{x_{n}\right\}_{n \in N_{0}}$ is a Cauchy sequence. Completeness of $X$ means that

$$
\lim _{n \rightarrow \infty} x_{n}=u \text { for some } u \in X \text {. }
$$

According to (19), we are aware of the fact that for any $\varepsilon>0$ there is $M \in N$ with

$$
p\left(x_{n}, x_{m}\right)<\varepsilon, \forall m>n>M,
$$

which together with (27) gives that

$$
0 \leq p\left(x_{n}, u\right) \leq \liminf _{m \rightarrow \infty} p\left(x_{n}, x_{m}\right) \leq \varepsilon, \forall n>M .
$$

It follows that

$$
\lim _{n \rightarrow \infty} p\left(x_{n}, u\right)=0
$$

Taking account of (2), (30), $(w, \psi) \in \Phi_{1} \times \Phi_{4}$, and Lemma 2.1 in [12], we infer that 


$$
\begin{aligned}
0 & \leq \underset{n \rightarrow \infty}{\limsup } \int_{0}^{p\left(f x_{n}, f u\right)} w(r) d r \\
& \leq \limsup _{n \rightarrow \infty}\left(\int_{0}^{p\left(x_{n}, u\right)} w(r) d r-\int_{0}^{\psi\left(p\left(x_{n}, u\right)\right)} w(r) d r\right) \\
& \leq \limsup _{n \rightarrow \infty} \int_{0}^{p\left(x_{n}, u\right)} w(r) d r-\liminf _{n \rightarrow \infty} \int_{0}^{\psi\left(p\left(x_{n}, u\right)\right)} w(r) d r \\
& \leq 0-\int_{0}^{\psi(0)} w(r) d r=0 .
\end{aligned}
$$

It follows that

$$
\lim _{n \rightarrow \infty} \int_{0}^{p\left(f x_{n}, f u\right)} w(r) d r=0
$$

Lemma 2.2 in [12] and the above equation give that

$$
\lim _{n \rightarrow \infty} p\left(f x_{n}, f u\right)=\lim _{n \rightarrow \infty} p\left(x_{n+1}, f u\right)=0 .
$$

We get from (1) in [8] and (17) that

$$
0 \leq p\left(x_{n}, f u\right) \leq p\left(x_{n}, x_{n+1}\right)+p\left(x_{n+1}, f u\right) \rightarrow 0 \text { as } n \rightarrow \infty .
$$

Clearly,

$$
\lim _{n \rightarrow \infty} p\left(x_{n}, f u\right)=0
$$
$=f u$.

Applying (30), (35), and Lemma 1 in [8], we gain that $u$

Secondly, we prove that $p(u, u)=0$. Suppose that $p(u, u$ )$>0$. In view of $(w, \psi) \in \Phi_{1} \times \Phi_{4}$ and (2), we receive that

$$
\begin{aligned}
0 & <\int_{0}^{p(u, u)} w(r) d r=\int_{0}^{p(f u, f u)} w(r) d r \\
& \leq \int_{0}^{p(u, u)} w(r) d r-\int_{0}^{\psi(p(u, u))} w(r) d r \\
& <\int_{0}^{p(u, u)} w(r) d r
\end{aligned}
$$

which is not possible. Hence, $p(u, u)=0$.

Thirdly, we assert the uniqueness of fixed points of $f$ in $X$. Assume that $f$ possesses two fixed points $u, v \in X$. We know, analogous to the proof of (36), that $p(u, u)=p(v, v)=0$. Assume that $p(u, v)>0$. Due to $(w, \psi) \in \Phi_{1} \times \Phi_{4}$ and (2), we deduce that

$$
\begin{aligned}
0 & <\int_{0}^{p(u, v)} w(r) d r=\int_{0}^{p(f u, f v)} w(r) d r \\
& \leq \int_{0}^{p(u, v)} w(r) d r-\int_{0}^{\psi(p(u, v))} w(r) d r \\
& <\int_{0}^{p(u, v)} w(r) d r
\end{aligned}
$$

which is ridiculous. Consequently, $p(u, v)=0$. Using Lemma 1 in [8] and $p(u, u)=0$, we obtain that $u=v$.

Theorem 4. Let $p$ be a $\omega$-distance in a complete metric space $(X, d)$ and let $f: X \rightarrow X$ satisfy that

$$
\int_{0}^{p(f x, f y)} w(r) d r \leq \int_{0}^{p(x, y)} w(r) d r-\int_{0}^{\psi(p(x, f y))} w(r) d r, \forall x, y \in X
$$

Here, $(w, \psi) \in \Phi_{2} \times \Phi_{4}$. Then, $f$ possesses a unique fixed point $u \in X$ such that $p(u, u)=0$,

$\lim _{n \rightarrow \infty} p\left(f^{n} x_{0}, u\right)=0$ and $\lim _{n \rightarrow \infty} f^{n} x_{0}=u$ for each $x_{0} \in X$.

Proof. Firstly, we show that $f$ possesses fixed points in $X$. Let $x_{0} \in X$ and $x_{n}=f^{n} x_{0}$ for each $n \in N_{0}$. Now, we divide the proof into two steps.

Step 5. Put $x_{n_{0}}=x_{n_{0}-1}$ for some $n_{0} \in N$. In addition, $x_{n_{0}-1}$ is a fixed point of $f$ and $\lim _{n \rightarrow \infty} f^{n} x_{0}=x_{n_{0}-1}$. Suppose that $p$ ( $\left.x_{n_{0}-1}, x_{n_{0}-1}\right)>0$. Owing to (38) and $(w, \psi) \in \Phi_{2} \times \Phi_{4}$, we acquire that

$$
\begin{aligned}
\int_{0}^{p\left(x_{n_{0}-1}, x_{n_{0}-1}\right)} w(r) d r= & \int_{0}^{p\left(f x_{n_{0}-1}, f x_{n_{0}-1}\right)} w(r) d r \\
\leq & \int_{0}^{p\left(x_{n_{0}-1}, x_{n_{0}-1}\right)} w(r) d r \\
& -\int_{0}^{\psi\left(p\left(x_{n_{0}-1}, f x_{n_{0}-1}\right)\right)} w(r) d r \\
= & \int_{0}^{p\left(x_{n_{0}-1}, x_{n_{0}-1}\right)} w(r) d r \\
& -\int_{0}^{\psi\left(p\left(x_{n_{0}-1}, x_{n_{0}-1}\right)\right)} w(r) d r \\
< & \int_{0}^{p\left(x_{n_{0}-1}, x_{n_{0}-1}\right)} w(r) d r
\end{aligned}
$$

which is ridiculous. Hence, $p\left(x_{n_{0}-1}, x_{n_{0}-1}\right)=0$, which means that

$$
\lim _{n \rightarrow \infty} p\left(f^{n} x_{0}, x_{n_{0}-1}\right)=p\left(x_{n_{0}-1}, x_{n_{0}-1}\right)=0 ;
$$

Step 6. $x_{n} \neq x_{n-1}$ for all $n \in N$. Assume that

$$
p\left(x_{n_{0}}, x_{n_{0}-1}\right)=0 \text { for some } n_{0} \in N \text {. }
$$


Using $(w, \psi) \in \Phi_{2} \times \Phi_{4}$, (38), and (42), we conclude that

$$
\begin{aligned}
0 & \leq \int_{0}^{p\left(x_{n_{0}+1}, x_{n_{0}}\right)} w(r) d r=\int_{0}^{p\left(f x_{n_{0}}, f x_{n_{0}-1}\right)} w(r) d r \\
& \leq \int_{0}^{p\left(x_{n_{0}}, x_{n_{0}-1}\right)} w(r) d r-\int_{0}^{\psi\left(p\left(x_{n_{0}}, f x_{n_{0}-1}\right)\right)} w(r) d r \\
& =\int_{0}^{p\left(x_{n_{0}}, x_{n_{0}-1}\right)} w(r) d r-\int_{0}^{\psi\left(p\left(x_{n_{0}}, x_{n_{0}}\right)\right)} w(r) d r \leq 0 .
\end{aligned}
$$

It becomes that

$$
\int_{0}^{p\left(x_{n_{0}+1}, x_{n_{0}}\right)} w(r) d r=0 .
$$

Thus, $w \in \Phi_{2}$ and the above equation guarantee that

$$
p\left(x_{n_{0}+1}, x_{n_{0}}\right)=0 .
$$

As a result of (42), (45), and (1) in [8], we deduce that

$$
0 \leq p\left(x_{n_{0}+1}, x_{n_{0}-1}\right) \leq p\left(x_{n_{0}+1}, x_{n_{0}}\right)+p\left(x_{n_{0}}, x_{n_{0}-1}\right)=0,
$$

in other words,

$$
p\left(x_{n_{0}+1}, x_{n_{0}-1}\right)=0 .
$$

From (45), (47), and Lemma 1 in [8], we obtain that $x_{n_{0}}$ $=x_{n_{0}-1}$, which is impossible, and, hence,

$$
p\left(x_{n}, x_{n-1}\right)>0, \forall n \in N \text {. }
$$

Suppose that there exists $q \in N$ with

$$
p\left(x_{q+1}, x_{q}\right)>p\left(x_{q}, x_{q-1}\right) .
$$

In light of (38), (48), (49), and $(w, \psi) \in \Phi_{2} \times \Phi_{4}$, we infer that

$$
\begin{aligned}
0< & \int_{0}^{p\left(x_{q}, x_{q-1}\right)} w(r) d r<\int_{0}^{p\left(x_{q+1}, x_{q}\right)} w(r) d r \\
= & \int_{0}^{p\left(f x_{q}, f_{q-1}\right)} w(r) d r \leq \int_{0}^{p\left(x_{q}, x_{q-1}\right)} w(r) d r \\
& \quad-\int_{0}^{\psi\left(p\left(x_{q}, x_{q-1}\right)\right)} w(r) d r=\int_{0}^{p\left(x_{q}, x_{q-1}\right)} w(r) d r \\
& -\int_{0}^{\psi\left(p\left(x_{q}, x_{q}\right)\right)} w(r) d r \leq \int_{0}^{p\left(x_{q}, x_{q-1}\right)} w(r) d r .
\end{aligned}
$$

It is ridiculous. By means of (48), we get that

$$
0<p\left(x_{n+1}, x_{n}\right) \leq p\left(x_{n}, x_{n-1}\right), \forall n \in N .
$$

Thus, (51) means that the sequence $\left\{p\left(x_{n+1}, x_{n}\right)\right\}_{n \in N_{0}}$ is both positive and decreasing. Consequently,

$$
\lim _{n \rightarrow \infty} p\left(x_{n+1}, x_{n}\right)=v \text { for some } v \geq 0 .
$$

Assume that

$$
p\left(x_{j+2}, x_{j}\right)>p\left(x_{j+1}, x_{j-1}\right) \text { for some } j \in N \text {. }
$$

In terms of (38), (53), and $(w, \psi) \in \Phi_{2} \times \Phi_{4}$, we attain that

$$
\begin{aligned}
0 & \leq \int_{0}^{p\left(x_{j+1}, x_{j-1}\right)} w(r) d r<\int_{0}^{p\left(x_{j+2}, x_{j}\right)} w(r) d r \\
= & \int_{0}^{p\left(f x_{j+1}, x_{j-1}\right)} w(r) d r \leq \int_{0}^{p\left(x_{j+1}, x_{j-1}\right)} w(r) d r \\
& \quad-\int_{0}^{\psi\left(p\left(x_{j+1}, f x_{j-1}\right)\right)} w(r) d r=\int_{0}^{p\left(x_{j+1}, x_{j-1}\right)} w(r) d r \\
& \quad-\int_{0}^{\psi\left(p\left(x_{j+1}, x_{j}\right)\right)} w(r) d r \leq \int_{0}^{p\left(x_{j+1}, x_{j-1}\right)} w(r) d r,
\end{aligned}
$$

which is ridiculous. Hence,

$$
0 \leq p\left(x_{n+2}, x_{n}\right) \leq p\left(x_{n+1}, x_{n-1}\right), \quad \forall n \in N .
$$

We get from (55) that the sequence $\left\{p\left(x_{n+2}, x_{n}\right)\right\}_{n \in N_{0}}$ is both nonnegative and nonincreasing. Thus,

$$
\lim _{n \rightarrow \infty} p\left(x_{n+2}, x_{n}\right)=b \text { for some } b \geq 0 \text {. }
$$

Assume that $v>0$. In view of (38), (52), (56), $(w, \psi) \in$ $\Phi_{2} \times \Phi_{4}$, and Lemma 2.1 in [12], we gain that

$$
\begin{aligned}
0 & \leq \int_{0}^{b} w(r) d r=\limsup _{n \rightarrow \infty} \int_{0}^{p\left(x_{n+2}, x_{n}\right)} w(r) d r \\
& =\limsup _{n \rightarrow \infty} \int_{0}^{p\left(f x_{n+1}, f x_{n-1}\right)} w(r) d r \\
& \leq \limsup _{n \rightarrow \infty}\left(\int_{0}^{p\left(x_{n+1}, x_{n-1}\right)} w(r) d r-\int_{0}^{\psi\left(p\left(x_{n+1}, x_{n-1}\right)\right)} w(r) d r\right) \\
& =\limsup _{n \rightarrow \infty}\left(\int_{0}^{p\left(x_{n+1}, x_{n-1}\right)} w(r) d r-\int_{0}^{\psi\left(p\left(x_{n+1}, x_{n}\right)\right)} w(r) d r\right) \\
& \leq \limsup _{n \rightarrow \infty}^{p\left(x_{n+1}, x_{n-1}\right)} w(r) d r-\liminf _{n \rightarrow \infty}^{\psi} \int_{0}^{\psi\left(p\left(x_{n+1}, x_{n}\right)\right)} w(r) d r \\
& \leq \int_{0}^{b} w(r) d r-\int_{0}^{\psi(v)} w(r) d r<\int_{0}^{b} w(r) d r .
\end{aligned}
$$

It is impossible. Thus, (18) is true. Suppose that (6) holds. 
Taking advantage of (6), (38), and $(w, \psi) \in \Phi_{2} \times \Phi_{4}$, we have

$$
\begin{aligned}
0 & \leq \int_{0}^{p\left(x_{n_{0}}, x_{n_{0}+1}\right)} w(r) d r=\int_{0}^{p\left(f x_{n_{0}-1}, f x_{n_{0}}\right)} w(r) d r \\
& \leq \int_{0}^{p\left(x_{n_{0}-1}, x_{n_{0}}\right)} w(r) d r-\int_{0}^{\psi\left(p\left(x_{n_{0}-1}, f x_{n_{0}}\right)\right)} w(r) d r \\
& =\int_{0}^{p\left(x_{n_{0}-1}, x_{n_{0}}\right)} w(r) d r-\int_{0}^{\psi\left(p\left(x_{n_{0}-1}, x_{n_{0}+1}\right)\right)} w(r) d r \leq 0 .
\end{aligned}
$$

It follows that

$$
\int_{0}^{p\left(x_{n_{0}}, x_{n_{0}+1}\right)} w(r) d r=0
$$

Thus, the above equation and $w \in \Phi_{2}$ give (9). Using (6), (9), and (1) in [8], we conclude that

$$
0 \leq p\left(x_{n_{0}-1}, x_{n_{0}+1}\right) \leq p\left(x_{n_{0}-1}, x_{n_{0}}\right)+p\left(x_{n_{0}}, x_{n_{0}+1}\right)=0
$$

that is, (11) holds. By virtue of (6), (11), and Lemma 1 in [8], we obtain that $x_{n_{0}}=x_{n_{0}+1}$, which is impossible. As a result, (12) holds. Assume that there exists $q \in N$ with

$$
p\left(x_{q}, x_{q+1}\right)>p\left(x_{q-1}, x_{q}\right) \text {. }
$$

We know from (12), (38), (61), and $(w, \psi) \in \Phi_{2} \times \Phi_{4}$ that

$$
\begin{aligned}
0< & \int_{0}^{p\left(x_{q-1}, x_{q}\right)} w(r) d r<\int_{0}^{p\left(x_{q}, x_{q+1}\right)} w(r) d r \\
= & \int_{0}^{p\left(f x_{q-1}, f x_{q}\right)} w(r) d r \leq \int_{0}^{p\left(x_{q-1}, x_{q}\right)} w(r) d r \\
& -\int_{0}^{\psi\left(p\left(x_{q-1}, f x_{q}\right)\right)} w(r) d r=\int_{0}^{p\left(x_{q-1}, x_{q}\right)} w(r) d r \\
& -\int_{0}^{\psi\left(p\left(x_{q-1}, x_{q+1}\right)\right)} w(r) d r \leq \int_{0}^{p\left(x_{q-1}, x_{q}\right)} w(r) d r,
\end{aligned}
$$

which is ridiculous. By means of (12), we obtain that

$$
0<p\left(x_{n}, x_{n+1}\right) \leq p\left(x_{n-1}, x_{n}\right), \forall n \in N
$$

With the help of (63), there is a real number $c \geq 0$ satisfying (15). Assume that $c>0$. Let $\limsup _{n \rightarrow \infty} p\left(x_{n}, x_{n}\right)=w$. Clearly, there exists a subsequence $\left\{x_{n_{k}}\right\}_{k \in N}$ of $\left\{x_{n}\right\}_{n \in N_{0}}$ with

$$
\lim _{k \rightarrow \infty} p\left(x_{n_{k}}, x_{n_{k}}\right)=w
$$

Note that (38) and $(w, \psi) \in \Phi_{2} \times \Phi_{4}$ infer that

$$
\begin{aligned}
0 & \leq \int_{0}^{p\left(x_{n+1}, x_{n}\right)} w(r) d r=\int_{0}^{p\left(f x_{n}, f x_{n-1}\right)} w(r) d r \\
& \leq \int_{0}^{p\left(x_{n}, x_{n-1}\right)} w(r) d r-\int_{0}^{\psi\left(p\left(x_{n}, f x_{n-1}\right)\right)} w(r) d r \\
& =\int_{0}^{p\left(x_{n}, x_{n-1}\right)} w(r) d r-\int_{0}^{\psi\left(p\left(x_{n}, x_{n}\right)\right)} w(r) d r \\
& \leq \int_{0}^{p\left(x_{n}, x_{n-1}\right)} w(r) d r, \forall n \in N .
\end{aligned}
$$

Letting $n \rightarrow \infty$ in (65) and utilizing (18), $w \in \Phi_{2}$ and Lemma 2.2 in [12], we make a conclusion that

$$
\lim _{n \rightarrow \infty}\left(\int_{0}^{p\left(x_{n}, x_{n-1}\right)} w(r) d r-\int_{0}^{\psi\left(p\left(x_{n}, x_{n}\right)\right)} w(r) d r\right)=0
$$

It follows that

$$
\begin{aligned}
\lim _{n \rightarrow \infty} \int_{0}^{\psi\left(p\left(x_{n}, x_{n}\right)\right)} w(r) d r= & \lim _{n \rightarrow \infty} \int_{0}^{p\left(x_{n}, x_{n-1}\right)} w(r) d r \\
& -\lim _{n \rightarrow \infty}\left(\int_{0}^{p\left(x_{n}, x_{n-1}\right)} w(r) d r-\int_{0}^{\psi\left(p\left(x_{n}, x_{n}\right)\right)} w(r) d r\right)=0 .
\end{aligned}
$$

In view of (18), (38), (64), (65), and (67), $(w, \psi) \in \Phi_{2} \times$ $\Phi_{4}$ and Lemma 2.2 in [12], we deduct that

$$
\begin{aligned}
0 & =\underset{k \rightarrow \infty}{\limsup } \int_{0}^{p\left(x_{n_{k}+1}, x_{n_{k}}\right)} w(r) d r=\limsup _{k \rightarrow \infty} \int_{0}^{p\left(f x_{n_{k}}, f x_{n_{k}-1}\right)} w(r) d r \\
& \leq \underset{k \rightarrow \infty}{\limsup }\left(\int_{0}^{p\left(x_{n_{k}}, x_{n_{k}-1}\right)} w(r) d r-\int_{0}^{\psi\left(p\left(x_{n_{k}}, f x_{n_{k}-1}\right)\right)} w(r) d r\right) \\
& =\underset{k \rightarrow \infty}{\limsup }\left(\int_{0}^{p\left(x_{n_{k}}, x_{n_{k}-1}\right)} w(r) d r-\int_{0}^{\psi\left(p\left(x_{n_{k}}, x_{n_{k}}\right)\right)} w(r) d r\right) \\
& \leq \underset{k \rightarrow \infty}{\limsup } \int_{0}^{p\left(x_{n_{k}}, x_{n_{k}-1}\right)} w(r) d r-\liminf _{k \rightarrow \infty} \int_{0}^{\psi\left(p\left(x_{n_{k}}, x_{n_{k}}\right)\right)} w(r) d r \\
& \leq 0-\int_{0}^{\psi(w)} w(r) d r,
\end{aligned}
$$

which together with $(w, \psi) \in \Phi_{2} \times \Phi_{4}$ yields that $w=0$. It is obvious that

$$
\lim _{n \rightarrow \infty} p\left(x_{n}, x_{n}\right)=0
$$

Using Lemma 2.2 in [12], (15), (38), (69), and $(w, \psi) \epsilon$ $\Phi_{2} \times \Phi_{4}$, we find that 


$$
\begin{aligned}
0 & =\underset{n \rightarrow \infty}{\limsup } \int_{0}^{p\left(x_{n+1}, x_{n+1}\right)} w(r) d r=\limsup _{n \rightarrow \infty} \int_{0}^{p\left(f x_{n}, f x_{n}\right)} w(r) d r \\
& \leq \limsup _{n \rightarrow \infty}\left(\int_{0}^{p\left(x_{n}, x_{n}\right)} w(r) d r-\int_{0}^{\psi\left(p\left(x_{n}, f x_{n}\right)\right)} w(r) d r\right) \\
& =\underset{n \rightarrow \infty}{\limsup }\left(\int_{0}^{p\left(x_{n}, x_{n}\right)} w(r) d r-\int_{0}^{\psi\left(p\left(x_{n}, x_{n+1}\right)\right)} w(r) d r\right) \\
& \leq \limsup _{n \rightarrow \infty} \int_{0}^{p\left(x_{n}, x_{n}\right)} w(r) d r-\liminf _{n \rightarrow \infty} \int_{0}^{\psi\left(p\left(x_{n}, x_{n+1}\right)\right)} w(r) d r \\
& \leq 0-\int_{0}^{\psi(c)} w(r) d r
\end{aligned}
$$

which together with $(w, \psi) \in \Phi_{2} \times \Phi_{4}$ implies that $c=0$. Thus, (17) holds.

Now, we assert that (19) holds. Otherwise, there is a real number $\varepsilon>0$ such that for arbitrary $k \in N$, there are $m(k)$, $n(k) \in N$ with (20) and (21). On account of (1) in [8] and (3.12), we gain that

$$
\begin{aligned}
\varepsilon< & p\left(x_{n(k)}, x_{m(k)}\right) \leq p\left(x_{n(k)}, x_{n(k)-1}\right)+p\left(x_{n(k)-1}, x_{m(k)}\right) \\
\leq & p\left(x_{n(k)}, x_{n(k)-1}\right)+p\left(x_{n(k)-1}, x_{m(k)-1}\right)+p\left(x_{m(k)-1}, x_{m(k)}\right) \\
\leq & p\left(x_{n(k)}, x_{n(k)-1}\right)+p\left(x_{n(k)-1}, x_{n(k)}\right)+p\left(x_{n(k)}, x_{m(k)-1}\right) \\
& +p\left(x_{m(k)-1}, x_{m(k)}\right) \leq p\left(x_{n(k)}, x_{n(k)-1}\right)+p\left(x_{n(k)-1}, x_{n(k)}\right) \\
& +\varepsilon+p\left(x_{m(k)-1}, x_{m(k)}\right), \forall k \in N .
\end{aligned}
$$

Letting $k \rightarrow \infty$ in (71) and making use of (17), (18), and (21), we require that

$$
\begin{aligned}
\lim _{k \rightarrow \infty} p\left(x_{n(k)}, x_{m(k)}\right) & =\lim _{k \rightarrow \infty} p\left(x_{n(k)-1}, x_{m(k)-1}\right) \\
& =\lim _{k \rightarrow \infty} p\left(x_{n(k)-1}, x_{m(k)}\right)=\varepsilon .
\end{aligned}
$$

Taking notice of (38), (72), $(w, \psi) \in \Phi_{2} \times \Phi_{4}$, and Lemma 2.1 in [12], we receive that

$$
\begin{aligned}
\int_{0}^{\varepsilon} w(r) d r & =\limsup _{k \rightarrow \infty} \int_{0}^{p\left(x_{n(k)}, x_{m(k)}\right)} w(r) d r \\
& =\limsup _{k \rightarrow \infty} \int_{0}^{p\left(f x_{n(k)-1}, f x_{m(k)-1}\right)} w(r) d r \\
& \leq \limsup _{k \rightarrow \infty}\left(\int_{0}^{p\left(x_{n(k)-1}, x_{m(k)-1}\right)} w(r) d r-\int_{0}^{\psi\left(p\left(x_{n(k)-1}, f x_{m(k)-1}\right)\right)} w(r) d r\right) \\
& =\limsup _{k \rightarrow \infty}\left(\int_{0}^{p\left(x_{n(k)-1}, x_{m(k)-1}\right)} w(r) d r-\int_{0}^{\psi\left(p\left(x_{n(k)-1}, x_{m(k)}\right)\right)} w(r) d r\right)
\end{aligned}
$$

$$
\begin{aligned}
& \leq \limsup _{k \rightarrow \infty} \int_{0}^{p\left(x_{n(k)-1}, x_{m(k)-1}\right)} w(r) d r-\liminf _{k \rightarrow \infty} \int_{0}^{\psi\left(p\left(x_{n(k)-1}, x_{m(k)}\right)\right)} w(r) d r \\
& \leq \int_{0}^{\varepsilon} w(r) d r-\int_{0}^{\psi(\varepsilon)} w(r) d r<\int_{0}^{\varepsilon} w(r) d r .
\end{aligned}
$$

It is ridiculous. That is, (19) is true.

We deduce, similar to the proof of Theorem 1, that (27) holds. It follows from (19) that for every real number $\varepsilon>0$ there is $M \in N$ with

$$
p\left(x_{n}, x_{m}\right)<\varepsilon, \forall m>n>M \text {, }
$$

which together with (2) in [8] and (27) gives that

$$
0 \leq p\left(x_{n}, u\right) \leq \liminf _{m \rightarrow \infty} p\left(x_{n}, x_{m}\right) \leq \varepsilon, \forall n>M,
$$

that is, (30) holds. In terms of (30), (38), $(w, \psi) \in \Phi_{2} \times \Phi_{4}$, and Lemma 2.1 in [12], we get that

$$
\begin{aligned}
0 & \leq \limsup _{n \rightarrow \infty} \int_{0}^{p\left(f x_{n}, f u\right)} w(r) d r \\
& \leq \underset{n \rightarrow \infty}{\limsup }\left(\int_{0}^{p\left(x_{n}, u\right)} w(r) d r-\int_{0}^{\psi\left(p\left(x_{n}, f u\right)\right)} w(r) d r\right) \\
& \leq \underset{n \rightarrow \infty}{\limsup } \int_{0}^{p\left(x_{n}, u\right)} w(r) d r-\liminf _{n \rightarrow \infty} \int_{0}^{\psi\left(p\left(x_{n}, f u\right)\right)} w(r) d r \\
& \leq 0-\liminf _{n \rightarrow \infty} \int_{0}^{\psi\left(p\left(x_{n}, f u\right)\right)} w(r) \mathrm{d} r \leq 0 .
\end{aligned}
$$

It follows that

$$
\lim _{n \rightarrow \infty} \int_{0}^{p\left(f x_{n}, f u\right)} w(r) d r=0
$$

Thus, Lemma 2.2 in [12] and the above equation ensure that

$$
\lim _{n \rightarrow \infty} p\left(f x_{n}, f u\right)=\lim _{n \rightarrow \infty} p\left(x_{n+1}, f u\right)=0
$$

In light of (1) in [8] and (17), we arrive at

$$
0 \leq p\left(x_{n}, f u\right) \leq p\left(x_{n}, x_{n+1}\right)+p\left(x_{n+1}, f u\right) \rightarrow 0 \text { as } n \rightarrow \infty,
$$

that is to say, (35) holds. By virtue of (30), (35) and Lemma 1 in [8], we have $u=f u$. 
Secondly, we assert that $p(u, u)=0$. Assume that $p(u, u)$ $>0$. Owing to (38) and $(w, \psi) \in \Phi_{2} \times \Phi_{4}$, we deduce that

$$
\begin{aligned}
0<\int_{0}^{p(u, u)} w(r) d r & =\int_{0}^{p(f u, f u)} w(r) d r \leq \int_{0}^{p(u, u)} w(r) d r-\int_{0}^{\psi(p(u, f u))} w(r) d r \\
& =\int_{0}^{p(u, u)} w(r) d r-\int_{0}^{\psi(p(u, u))} w(r) d r<\int_{0}^{p(u, u)} w(r) d r .
\end{aligned}
$$

It is ridiculous. Hence, $p(u, u)=0$.

Thirdly, we show the uniqueness of fixed points of $f$ in $X$. Assume that $f$ possesses two fixed points $u, v \in X$. We get, similar to the proof of $(80)$, that $p(u, u)=p(v, v)=0$. Assume that $p(u, v)>0$. Taking account of $(w, \psi) \in \Phi_{2} \times \Phi_{4}$ and (38), we get that

$$
\begin{aligned}
0<\int_{0}^{p(u, v)} w(r) d r & =\int_{0}^{p(f u, f v)} w(r) d r \leq \int_{0}^{p(u, v)} w(r) d r-\int_{0}^{\psi(p(u, f v))} w(r) d r \\
& =\int_{0}^{p(u, v)} w(r) d r-\int_{0}^{\psi(p(u, v))} w(r) d r<\int_{0}^{p(u, v)} w(r) d r,
\end{aligned}
$$

which is ridiculous. Therefore, $p(u, v)=0$. It follows from $p$ $(u, u)=0$ and Lemma 1 in [8] that $u=v$.

Theorem 7. Let $p$ be a $\omega$-distance in a complete metric space $(X, d)$ and let $f: X \rightarrow X$ satisfy that

$$
\int_{0}^{p(f x, f y)} w(r) d r \leq \int_{0}^{p(x, y)} w(r) d r-\int_{0}^{\psi(p(f x, y))} w(r) d r, \forall x, y \in X,
$$

here $(w, \psi) \in \Phi_{2} \times \Phi_{4}$. Then, $f$ possesses a unique fixed point $u \in X$ satisfying $p(u, u)=0$,

$$
\lim _{n \rightarrow \infty} p\left(f^{n} x_{0}, u\right)=0 \text { and } \lim _{n \rightarrow \infty} f^{n} x_{0}=u \text { for each } x_{0} \in X
$$

Proof. Firstly, we demonstrate that $f$ possesses fixed points in $X$. Let $x_{0} \in X$ and $x_{n}=f^{n} x_{0}$ for each $n \in N_{0}$. Now, we consider two cases below:

Case 8. $x_{n_{0}}=x_{n_{0}-1}$ for some $n_{0} \in N$. Since $x_{n_{0}-1}$ is a fixed point of $f$, it follows that $\lim _{n \rightarrow \infty} f^{n} x_{0}=x_{n_{0}-1}$. Assume that $p($ $\left.x_{n_{0}-1}, x_{n_{0}-1}\right)>0$. Due to $(82)$ and $(\mathrm{w}, \psi) \in \Phi_{2} \times \Phi_{4}$, we have

$$
\begin{aligned}
\int_{0}^{p\left(x_{n_{0}-1}, x_{n_{0}-1}\right)} w(r) d r= & \int_{0}^{p\left(f x_{n_{0}-1}, f x_{n_{0}-1}\right)} w(r) d r \leq \int_{0}^{p\left(x_{n_{0}-1}, x_{n_{0}-1}\right)} w(r) d r \\
& -\int_{0}^{\psi\left(p\left(f x_{n_{0}-1}, x_{n_{0}-1}\right)\right)} w(r) d r \\
= & \int_{0}^{p\left(x_{n_{0}-1}, x_{n_{0}-1}\right)} w(r) d r-\int_{0}^{\psi\left(p\left(x_{n_{0}-1}, x_{n_{0}-1}\right)\right)} w(r) d r \\
& <\int_{0}^{p\left(x_{n_{0-1}-1}, x_{n_{0}-1}\right)} w(r) d r,
\end{aligned}
$$

which is absurd. Hence, $p\left(x_{n_{0}-1}, x_{n_{0}-1}\right)=0$ and

$$
\lim _{n \rightarrow \infty} p\left(f^{n} x_{0}, x_{n_{0}-1}\right)=p\left(x_{n_{0}-1}, x_{n_{0}-1}\right)=0 .
$$

Case 9. $x_{n} \neq x_{n-1}$ for all $n \in N$. Assume that (6) holds. In view of (6), (82), and $(w, \psi) \in \Phi_{2} \times \Phi_{4}$, we obtain that

$$
\begin{aligned}
0 & \leq \int_{0}^{p\left(x_{n_{0}}, x_{n_{0}+1}\right)} w(r) d r=\int_{0}^{p\left(f x_{n_{0}-1}, f x_{n_{0}}\right)} w(r) d r \\
& \leq \int_{0}^{p\left(x_{n_{0}-1}, x_{n_{0}}\right)} w(r) d r-\int_{0}^{\psi\left(p\left(f x_{n_{0}-1}, x_{n_{0}}\right)\right)} w(r) d r \\
& =\int_{0}^{p\left(x_{n_{0}-1}, x_{n_{0}}\right)} w(r) d r-\int_{0}^{\psi\left(p\left(x_{n_{0}}, x_{n_{0}}\right)\right)} w(r) d r \leq 0,
\end{aligned}
$$

which means that

$$
\int_{0}^{p\left(x_{n_{0}}, x_{n_{0}+1}\right)} w(r) d r=0
$$

Combining $w \in \Phi_{2}$ and the above equation, we get (3.3). We gain from (6), (9), and $\left(p_{1}\right)$ that

$$
0 \leq p\left(x_{n_{0}-1}, x_{n_{0}+1}\right) \leq p\left(x_{n_{0}-1}, x_{n_{0}}\right)+p\left(x_{n_{0}}, x_{n_{0}+1}\right)=0,
$$

in other words, (11) sets up. In terms of (6), (11), and Lemma 1 in [8], we know immediately that $x_{n_{0}}=x_{n_{0}+1}$, which is absurd, and, hence, (12) is true. Assume that there is $q \in N$ satisfying (61). We conclude from (12), (61), (82), and ( $w$, $\psi) \in \Phi_{2} \times \Phi_{4}$ that

$$
\begin{aligned}
0 & <\int_{0}^{p\left(x_{q-1}, x_{q}\right)} w(r) d r<\int_{0}^{p\left(x_{q}, x_{q+1}\right)} w(r) d r=\int_{0}^{p\left(f x_{q-1}, f x_{q}\right)} w(r) d r \\
& \leq \int_{0}^{p\left(x_{q-1}, x_{q}\right)} w(r) d r-\int_{0}^{\psi\left(p\left(f x_{q-1}, x_{q}\right)\right)} w(r) d r \\
& =\int_{0}^{p\left(x_{q-1}, x_{q}\right)} w(r) d r-\int_{0}^{\psi\left(p\left(x_{q}, x_{q}\right)\right)} w(r) d r \leq \int_{0}^{p\left(x_{q-1}, x_{q}\right)} w(r) d r,
\end{aligned}
$$

which is impossible. Hence, (63) is true. It follows from (63) that there is a real number $c \geq 0$ with (15). Assume that there 
is $j \in N$ with

$$
p\left(x_{j}, x_{j+2}\right)>p\left(x_{j-1}, x_{j+1}\right) .
$$

In terms of (82), (90), and $(w, \psi) \in \Phi_{2} \times \Phi_{4}$, we infer that

$$
\begin{aligned}
0 & \leq \int_{0}^{p\left(x_{j-1}, x_{j+1}\right)} w(r) d r<\int_{0}^{p\left(x_{j}, x_{j+2}\right)} w(r) d r=\int_{0}^{p\left(f x_{j-1}, f x_{j+1}\right)} w(r) d r \\
& \leq \int_{0}^{p\left(x_{j-1}, x_{j+1}\right)} w(r) d r-\int_{0}^{\psi\left(p\left(f x_{j-1}, x_{j+1}\right)\right)} w(r) d r \\
& =\int_{0}^{p\left(x_{j-1}, x_{j+1}\right)} w(r) d r-\int_{0}^{\psi\left(p\left(x_{j}, x_{j+1}\right)\right)} w(r) d r \leq \int_{0}^{p\left(x_{j-1}, x_{j+1}\right)} w(r) d r .
\end{aligned}
$$

It is absurd, and, hence,

$$
0 \leq p\left(x_{n}, x_{n+2}\right) \leq p\left(x_{n-1}, x_{n+1}\right), \forall n \in N .
$$

(92) means that $\left\{p\left(x_{n}, x_{n+2}\right)\right\}_{n \in N_{0}}$ is both nonnegative and nonincreasing. Consequently,

$$
\lim _{n \rightarrow \infty} p\left(x_{n}, x_{n+2}\right)=z \text { for some constant } z \geq 0 \text {. }
$$

Assume that $c>0$. Owing to (15), (82), (93), $(w, \psi) \epsilon$ $\Phi_{2} \times \Phi_{4}$, and Lemma 2.1 in [12], we get that

$$
\begin{aligned}
0 & \leq \int_{0}^{z} w(r) d r=\limsup _{n \rightarrow \infty} \int_{0}^{p\left(x_{n}, x_{n+2}\right)} w(r) d r \\
& =\limsup _{n \rightarrow \infty} \int_{0}^{p\left(f x_{n-1}, f x_{n+1}\right)} w(r) d r \\
& \leq \limsup _{n \rightarrow \infty}\left(\int_{0}^{p\left(x_{n-1}, x_{n+1}\right)} w(r) d r-\int_{0}^{\psi\left(p\left(f x_{n-1}, x_{n+1}\right)\right)} w(r) d r\right) \\
& =\limsup _{n \rightarrow \infty}\left(\int_{0}^{p\left(x_{n-1}, x_{n+1}\right)} w(r) d r-\int_{0}^{\psi\left(p\left(x_{n}, x_{n+1}\right)\right)} w(r) d r\right) \\
& \leq \limsup _{n \rightarrow \infty}^{p\left(x_{n-1}, x_{n+1}\right)} w(r) d r-\liminf _{n \rightarrow \infty}^{\psi} \int_{0}^{\psi\left(p\left(x_{n}, x_{n+1}\right)\right)} w(r) d r \\
& \leq \int_{0}^{z} w(r) d r-\int_{0}^{\psi(c)} w(r) d r<\int_{0}^{z} w(r) d r .
\end{aligned}
$$

It is contradictive. Thus, (17) is true. Suppose that (42) holds. We infer from (42), (82), and $(w, \psi) \in \Phi_{2} \times \Phi_{4}$ that

$$
\begin{aligned}
0 & \leq \int_{0}^{p\left(x_{n_{0}+1}, x_{n_{0}}\right)} w(r) d r=\int_{0}^{p\left(f x_{n_{0}}, f x_{n_{0}-1}\right)} w(r) d r \\
& \leq \int_{0}^{p\left(x_{n_{0}}, x_{n_{0}-1}\right)} w(r) d r-\int_{0}^{\psi\left(p\left(f x_{n_{0}}, x_{n_{0}-1}\right)\right)} w(r) d r \\
& =\int_{0}^{p\left(x_{n_{0}}, x_{n_{0}-1}\right)} w(r) d r-\int_{0}^{\psi\left(p\left(x_{n_{0}+1}, x_{n_{0}-1}\right)\right)} w(r) d r \leq 0,
\end{aligned}
$$

that is,

$$
\int_{0}^{p\left(x_{n_{0}+1}, x_{n_{0}}\right)} w(r) d r=0
$$

Thus, (45) follows from the above equation and $w \in \Phi_{2}$. We deduct from (42), (45), and (1) in [8] that

$$
0 \leq p\left(x_{n_{0}+1}, x_{n_{0}-1}\right) \leq p\left(x_{n_{0}+1}, x_{n_{0}}\right)+p\left(x_{n_{0}}, x_{n_{0}-1}\right)=0,
$$

that is to say, (47) holds. Thus, $x_{n_{0}}=x_{n_{0}-1}$ is easily obtained from (45), (47), and Lemma 1 in [8], which is ridiculous. As a result, (48) holds. Suppose that there exists $q \in N$ satisfying (49). By virtue of (48), (49), (82), and $(w, \psi) \in \Phi_{2} \times$ $\Phi_{4}$, we know that

$$
\begin{aligned}
0 & <\int_{0}^{p\left(x_{q}, x_{q-1}\right)} w(r) d r<\int_{0}^{p\left(x_{q+1}, x_{q}\right)} w(r) d r=\int_{0}^{p\left(f x_{q}, f x_{q-1}\right)} w(r) d r \\
& \leq \int_{0}^{p\left(x_{q}, x_{q-1}\right)} w(r) d r-\int_{0}^{\psi\left(p\left(f x_{q}, x_{q-1}\right)\right)} w(r) d r \\
& =\int_{0}^{p\left(x_{q}, x_{q-1}\right)} w(r) d r-\int_{0}^{\psi\left(p\left(x_{q+1}, x_{q-1}\right)\right)} w(r) d r \\
& \leq \int_{0}^{p\left(x_{q}, x_{q-1}\right)} w(r) d r
\end{aligned}
$$

which is ridiculous. By means of (48), we have (51). It follows from (51) that the sequence $\left\{p\left(x_{n+1}, x_{n}\right)\right\}_{n \in N_{0}}$ is both positive and decreasing, which yields (52) for some a constant $v \geq 0$. Suppose that $v>0$. Put limsup $\operatorname{lio}_{n \rightarrow \infty} p\left(x_{n}, x_{n}\right)=w$. Obviously, there is a subsequence $\left\{x_{n_{k}}\right\}_{k \in N}$ of $\left\{x_{n}\right\}_{n \in N_{0}}$ with (64). Using (82), and $(w, \psi) \in \Phi_{2} \times \Phi_{4}$, we deduce that

$$
\begin{aligned}
0 & \leq \int_{0}^{p\left(x_{n}, x_{n+1}\right)} w(r) d r=\int_{0}^{p\left(f x_{n-1}, x_{n}\right)} w(r) d r \\
& \leq \int_{0}^{p\left(x_{n-1}, x_{n}\right)} w(r) d r-\int_{0}^{\psi\left(p\left(f x_{n-1}, x_{n}\right)\right)} w(r) d r \\
& =\int_{0}^{p\left(x_{n-1}, x_{n}\right)} w(r) d r-\int_{0}^{\psi\left(p\left(x_{n}, x_{n}\right)\right)} w(r) d r \\
& \leq \int_{0}^{p\left(x_{n-1}, x_{n}\right)} w(r) d r, \quad \forall n \in N .
\end{aligned}
$$

Letting $n \rightarrow \infty$ in (99) and using (17), $w \in \Phi_{2}$ and Lemma 2.2 in [12], we find that

$$
\lim _{n \rightarrow \infty}\left(\int_{0}^{p\left(x_{n-1}, x_{n}\right)} w(r) d r-\int_{0}^{\psi\left(p\left(x_{n}, x_{n}\right)\right)} w(r) d r\right)=0 .
$$


It follows that

$$
\begin{aligned}
\lim _{n \rightarrow \infty} \int_{0}^{\psi\left(p\left(x_{n}, x_{n}\right)\right)} w(r) d r= & \lim _{n \rightarrow \infty} \int_{0}^{p\left(x_{n-1}, x_{n}\right)} w(r) d r \\
& -\lim _{n \rightarrow \infty}\left(\int_{0}^{p\left(x_{n-1}, x_{n}\right)} w(r) d r\right. \\
& \left.-\int_{0}^{\psi\left(p\left(x_{n}, x_{n}\right)\right)} w(r) d r\right)=0 .
\end{aligned}
$$

We attain from Lemma 2.2 in [12], (17), (64), (82), (99), (101), and $(w, \psi) \in \Phi_{2} \times \Phi_{4}$ that

$$
\begin{aligned}
0 & =\underset{k \rightarrow \infty}{\limsup } \int_{0}^{p\left(x_{n_{k}}, x_{n_{k}+1}\right)} w(r) d r=\limsup _{k \rightarrow \infty} \int_{0}^{p\left(f x_{n_{k}-1}, f x_{n_{k}}\right)} w(r) d r \\
& \leq \underset{k \rightarrow \infty}{\limsup }\left(\int_{0}^{p\left(x_{n_{k}-1}, x_{n_{k}}\right)} w(r) d r-\int_{0}^{\psi\left(p\left(f x_{n_{k}-1}, x_{n_{k}}\right)\right)} w(r) d r\right) \\
& =\underset{k \rightarrow \infty}{\limsup }\left(\int_{0}^{p\left(x_{n_{k}-1}, x_{n_{k}}\right)} w(r) d r-\int_{0}^{\psi\left(p\left(x_{n_{k}}, x_{n_{k}}\right)\right)} w(r) d r\right) \\
& \leq \underset{k \rightarrow \infty}{\limsup } \int_{0}^{p\left(x_{n_{k}-1}, x_{n_{k}}\right)} w(r) d r-\liminf _{k \rightarrow \infty} \int_{0}^{\psi\left(p\left(x_{n_{k}}, x_{n_{k}}\right)\right)} w(r) d r \\
& \leq 0-\int_{0}^{\psi(w)} w(r) d r .
\end{aligned}
$$

It follows that $\int_{0}^{\psi(w)} w(r) d r \leq 0$. By virtue of $(w, \psi) \in \Phi_{2}$ $\times \Phi_{4}$, we have $\int_{0}^{\psi(w)} w(r) d r=0$ and $w=0$. It means that (69) holds. In view of (52), (69), (82), $(w, \psi) \in \Phi_{2} \times \Phi_{4}$, and Lemma 2.2 in [12], we infer that

$$
\begin{aligned}
0 & =\limsup _{n \rightarrow \infty} \int_{0}^{p\left(x_{n+1}, x_{n+1}\right)} w(r) d r=\limsup _{n \rightarrow \infty} \int_{0}^{p\left(f x_{n}, f x_{n}\right)} w(r) d r \\
& \leq \limsup _{n \rightarrow \infty}\left(\int_{0}^{p\left(x_{n}, x_{n}\right)} w(r) d r-\int_{0}^{\psi\left(p\left(f x_{n}, x_{n}\right)\right)} w(r) d r\right) \\
& =\underset{n \rightarrow \infty}{\limsup }\left(\int_{0}^{p\left(x_{n}, x_{n}\right)} w(r) d r-\int_{0}^{\psi\left(p\left(x_{n+1}, x_{n}\right)\right)} w(r) d r\right) \\
& \leq \limsup _{n \rightarrow \infty} \int_{0}^{p\left(x_{n}, x_{n}\right)} w(\mathrm{r}) d r-\liminf _{n \rightarrow \infty} \int_{0}^{\psi\left(p\left(x_{n+1}, x_{n}\right)\right)} w(r) d r \\
& \leq 0-\int_{0}^{\psi(v)} w(r) d r,
\end{aligned}
$$

which yields that $\int_{0}^{\psi(v)} w(r) d r \leq 0$. Using $(w, \psi) \in \Phi_{2} \times \Phi_{4}$, we obtain that $\int_{0}^{\psi(v)} w(r) d r=0$ and $v=0$. Thus, (3.9) holds.

Now, we prove that (19) holds. Suppose that there is an $\varepsilon>0$ such that for arbitrary $k \in N,(20),(21)$, and (22) hold for some $m(k), n(k) \in N$. As $k \rightarrow \infty$ in (3.13) and by virtue of (17), (18), and (21), we acquire that

$$
\begin{aligned}
\lim _{k \rightarrow \infty} p\left(x_{n(k)}, x_{m(k)}\right) & =\lim _{k \rightarrow \infty} p\left(x_{n(k)-1}, x_{m(k)-1}\right) \\
& =\lim _{k \rightarrow \infty} p\left(x_{n(k)}, x_{m(k)-1}\right)=\varepsilon .
\end{aligned}
$$

In terms of Lemma 2.1 in [12], (82), (104), and $(w, \psi)$ $\in \Phi_{2} \times \Phi_{4}$, we are aware of the fact that

$$
\begin{aligned}
& \int_{0}^{\varepsilon} w(r) d r=\limsup _{k \rightarrow \infty} \int_{0}^{p\left(x_{n(k)}, x_{m(k)}\right)} w(r) d r \\
& =\underset{k \rightarrow \infty}{\limsup } \int_{0}^{p\left(f x_{n(k)-1}, f x_{m(k)-1}\right)} w(r) d r \\
& \leq \underset{k \rightarrow \infty}{\limsup }\left(\int_{0}^{p\left(x_{n(k)-1}, x_{m(k)-1}\right)} w(r) d r\right. \\
& \left.-\int_{0}^{\psi\left(p\left(f x_{n(k)-1}, x_{m(k)-1}\right)\right)} w(r) d r\right) \\
& =\underset{k \rightarrow \infty}{\limsup }\left(\int_{0}^{p\left(x_{n(k)-1}, x_{m(k)-1}\right)} w(r) d r\right. \\
& \left.-\int_{0}^{\psi\left(p\left(x_{n(k)}, x_{m(k)-1}\right)\right)} w(r) d r\right) \\
& \leq \limsup _{k \rightarrow \infty} \int_{0}^{p\left(x_{n(k)-1}, x_{m(\mathrm{k})-1}\right)} w(r) d r \\
& -\liminf _{k \rightarrow \infty} \int_{0}^{\psi\left(p\left(x_{n(k)}, x_{m(k)-1}\right)\right)} w(r) d r \\
& \leq \int_{0}^{\varepsilon} w(r) d r-\int_{0}^{\psi(\varepsilon)} w(r) d r<\int_{0}^{\varepsilon} w(r) d r,
\end{aligned}
$$

which is absurd. Thus, (19) is true.

We infer, similar to the proof of Theorem 1, that (27) holds. It follows from (19) that for each $\varepsilon>0$ there is $M \epsilon$ $N$ with

$$
p\left(x_{n}, x_{m}\right)<\varepsilon, \forall m>n>M,
$$

which together with (2) in [8] and (27) gets that

$$
0 \leq p\left(x_{n}, u\right) \leq \liminf _{m \rightarrow \infty} p\left(x_{n}, x_{m}\right) \leq \varepsilon, \forall n>M,
$$

that is, (30) holds. On account of Lemma 2.1 in [12], (30), (82), and $(w, \psi) \in \Phi_{2} \times \Phi_{4}$, we deduct that

$$
\begin{array}{r}
0 \leq \limsup _{n \rightarrow \infty} \int_{0}^{p\left(f x_{n}, f u\right)} w(r) d r \leq \limsup _{n \rightarrow \infty}\left(\int_{0}^{p\left(x_{n}, u\right)} w(r) d r-\int_{0}^{\psi\left(p\left(f x_{n}, u\right)\right)} w(r) d r\right) \\
\quad \leq \limsup _{n \rightarrow \infty} \int_{0}^{p\left(x_{n}, u\right)} w(r) d r-\liminf _{n \rightarrow \infty} \int_{0}^{\psi\left(p\left(x_{n+1}, u\right)\right)} w(r) d r \leq 0-\int_{0}^{\psi(0)} w(r) d r=0,
\end{array}
$$


in other words,

$$
\lim _{n \rightarrow \infty} \int_{0}^{p\left(f x_{n}, f u\right)} w(r) d r=0
$$

Lemma 2.2 in [12] and the above equation give that

$$
\lim _{n \rightarrow \infty} p\left(f x_{n}, f u\right)=\lim _{n \rightarrow \infty} p\left(x_{n+1}, f u\right)=0 .
$$

In light of (1) in [8] and (17), we attain that

$$
0 \leq p\left(x_{n}, f u\right) \leq p\left(x_{n}, x_{n+1}\right)+p\left(x_{n+1}, f u\right) \rightarrow 0 \text { as } n \rightarrow \infty,
$$

that is to say, (35) holds. Using (30), (35), and Lemma 1 in [8], we have $u=f u$.

Secondly, we prove that $p(u, u)=0$. Assume that $p(u, u)$ $>0$. Because of $(82)$ and $(w, \psi) \in \Phi_{2} \times \Phi_{4}$, we deduce that

$$
\begin{aligned}
0 & <\int_{0}^{p(u, u)} w(r) d r=\int_{0}^{p(f u, f u)} w(r) d r \leq \int_{0}^{p(u, u)} w(r) d r-\int_{0}^{\psi(p(f u, u))} w(r) d r \\
& =\int_{0}^{p(u, u)} w(r) d r-\int_{0}^{\psi(p(u, u))} w(r) d r<\int_{0}^{p(u, u)} w(r) d r,
\end{aligned}
$$

which is impossible. Hence, $p(u, u)=0$.

Thirdly, we assert the uniqueness of fixed points of $f$ in $X$. Assume that $f$ possesses two fixed points $u, v \in X$. We deduce, similar to the proof of (112), that $p(u, u)=p(v, v)$ $=0$. Assume that $p(u, v)>0$. On account of $(82)$ and $(w, \psi$ )$\in \Phi_{2} \times \Phi_{4}$, we get that

$$
\begin{aligned}
0 & <\int_{0}^{p(u, v)} w(r) d r=\int_{0}^{p(f u, f v)} w(r) d r \leq \int_{0}^{p(u, v)} w(r) d r-\int_{0}^{\psi(p(f u, v))} w(r) d r \\
& =\int_{0}^{p(u, v)} w(r) d r-\int_{0}^{\psi(p(u, v))} w(r) d r<\int_{0}^{p(u, v)} w(r) d r,
\end{aligned}
$$

which is ridiculous. Therefore, $p(u, v)=0$. Using $p(u, u)=0$ and Lemma 1 in [8], we infer immediately that $u=v$.

We have, similar to the proof of Theorem 1, the result below and omit its proof.

Theorem 10. Let $p$ be a $\omega$-distance in a complete metric space $(X, d)$ and let $f: X \rightarrow X$ satisfy that

$$
\int_{0}^{p(f x, f y)} w(r) d r \leq \int_{0}^{p(x, y)} w(r) d r-\int_{0}^{\psi(p(f x, f y))} w(r) d r, \forall x, y \in X .
$$

Here, $(w, \psi) \in \Phi_{1} \times \Phi_{4}$. Then, $f$ possesses a unique fixed point $u \in X$ such that $p(u, u)=0$,

$$
\lim _{n \rightarrow \infty} p\left(f^{n} x_{0}, u\right)=0 \text { and } \lim _{n \rightarrow \infty} f^{n} x_{0}=u \text { for each } x_{0} \in X .
$$

\section{Four Examples}

Now, we give four examples to explain the fixed point results obtained in Section 3.

Remark 11. Letting $p(x, y)=d(x, y), \forall x, y \in X$, we deduce that Theorem 1 reduces to Theorem 2.1 in [14], which generalizes Theorem 1 in [15]. On the other hand, the example below proves that Theorem 1 extends indeed these results in $[14,15]$ and differs from Theorem 2.1 in [1].

Example 12. Let $X=[0,6], d(x, y)=|x-y|$ and $p(x, y)=y / 2$ $, \forall x, y \in X$. Let $f: X \rightarrow X, w$ and $\psi: R^{+} \rightarrow R^{+}$be defined by, respectively,

$$
f x=2 x-x^{2}, \forall x \in\left(\frac{6}{5}, 2\right], 0, \forall x \in\left[0, \frac{6}{5}\right] \cup(2,6]
$$

and

$$
w(r)=2, \quad \psi(r)=\frac{1}{3} r^{2}, \quad \forall r \in R^{+}
$$

It follows that $p$ is a $\omega$-distance in $X$ and $(w, \psi) \in \Phi_{1} \times \Phi_{4}$ . Put $x, y \in X$. In order to check (2), we consider two cases below:

Case 13. $(x, y) \in X \times(6 / 5,2]$. It follows that

$$
\begin{aligned}
\int_{0}^{p(f x, f y)} w(r) d r & =\int_{0}^{y-\frac{1}{2} y^{2}} 2 d r=2 y-y^{2} \leq y-\frac{1}{6} y^{2}=\int_{0}^{\frac{y}{2}} 2 d r-\int_{0}^{\frac{1}{12} y^{2}} 2 d r \\
& =\int_{0}^{p(x, y)} w(r) d r-\int_{0}^{\psi(p(x, y))} w(r) d r .
\end{aligned}
$$

Case 14. $(x, y) \in X \times[0,6 / 5] \cup(2,6]$. Note that

$$
\int_{0}^{p(f x, f y)} w(r) d r=0 \leq y-\frac{1}{6} y^{2}=\int_{0}^{p(x, y)} w(r) d r-\int_{0}^{\psi(p(x . y))} w(r) d r .
$$

That is, (2) is true. Hence, the conditions of Theorem 1 are fulfilled. Thus, Theorem 1 ensures that $f$ possesses a unique fixed point in $X$. Now, we need to prove that Theorem 2.1 in [1], Theorem 2.1 in [14], and Theorem 1 in [15] are useless in checking the existence of fixed points for the mapping $f$ in $X$. 
If there is $\psi \in \Phi_{3}$ satisfying the conditions of Theorem 1 in [15], we know that

$$
\frac{21}{25}=d\left(f \frac{7}{5}, f 1\right) \leq d\left(\frac{7}{5}, 1\right)-\psi\left(d\left(\frac{7}{5}, 1\right)\right)<\frac{2}{5}
$$

which is absurd.

If there are $c \in(0,1)$ and $w \in \Phi_{1}$ satisfying the conditions of Theorem 2.1 in [1], we attain that

$$
\begin{aligned}
0 & <\int_{0}^{\frac{3}{4}} w(r) d r=\int_{0}^{d\left(f_{\frac{3}{4}}^{3}, \frac{3}{2}\right)} w(r) d r \\
& \leq c \int_{0}^{d\left(\frac{3}{4}, \frac{3}{2}\right)} w(r) d r<\int_{0}^{\frac{3}{4}} w(r) d r
\end{aligned}
$$

which is ridiculous.

If there is $(w, \psi) \in \Phi_{1} \times \Phi_{4}$ satisfying the conditions of Theorem 2.1 in [14], we conclude that

$$
\begin{aligned}
0 & <\int_{0}^{\frac{24}{25}} w(r) d r=\limsup _{y \rightarrow \rightarrow^{+}} \int_{0}^{\left|0-\left(2 y-y^{2}\right)\right|} w(r) d r \\
& =\limsup _{y \rightarrow \frac{6}{5}^{+}} \int_{0}^{d\left(f \frac{6}{5}, f y\right)} w(r) d r \\
& \leq \limsup _{y \rightarrow \frac{6^{+}}{5}}\left(\int_{0}^{d\left(\frac{6}{5}, y\right)} w(r) d r-\int_{0}^{\psi\left(d\left(\frac{6}{5}, y\right)\right)} w(r) d r\right) \\
& \leq \limsup _{y \rightarrow \frac{6^{+}}{5}} \int_{0}^{d\left(\frac{6}{5}, y\right)} w(r) d r-\liminf _{y \rightarrow \frac{6^{+}}{5}} \int_{0}^{\psi\left(d\left(\frac{6}{5}, y\right)\right)} w(r) d r \\
& \leq 0-\int_{0}^{\psi(0)} w(r) d r=0,
\end{aligned}
$$

which is impossible.

Remark 15. Examples 16, 21, and 26 explain that Theorems 4, 7 , and 10 are different from Theorem 2.1 in [14].

Example 16. Let $X=R^{+}, d(x, y)=|x-y|$ and $p(x, y)=x+y$ $, \forall x, y \in X$. Let $f: X \rightarrow X, w$ and $\psi: R^{+} \rightarrow R^{+}$be defined by, respectively,

$$
f x=\frac{x}{3}, \forall x \in[0,1], \frac{x}{4}, \forall x \in(1,+\infty),
$$

and

$$
w(r)=2 r, \psi(r)=\frac{r}{2}, \forall r \in R^{+}
$$

Evidently, $p$ is a $\omega$-distance in $X$ and $(w, \psi) \in \Phi_{2} \times \Phi_{4}$. Let $x, y \in X$. For the sake of verifying (38), we take into account the following four possible cases:
Case 17. $(x, y) \in[0,1] \times[0,1]$. Note that

$$
\begin{aligned}
\int_{0}^{p(f x, f y)} w(r) d r & =\int_{0}^{\frac{x+y}{3}} 2 t d t=\frac{1}{9}(x+y)^{2} \leq(x+y)^{2}-\frac{1}{4}\left(x+\frac{y}{3}\right)^{2} \\
& =\int_{0}^{x+y} 2 t d t-\int_{0}^{\psi\left(x+\frac{y}{3}\right)} 2 t d t \\
& =\int_{0}^{p(x, y)} w(r) d r-\int_{0}^{\psi(p(x, f y))} w(r) d r
\end{aligned}
$$

Case 18. $(x, y) \in[0,1] \times(1,+\infty)$. Obviously,

$$
\begin{aligned}
\int_{0}^{p(f x, f y)} w(r) d r & =\int_{0}^{\frac{x}{3}+\frac{y}{4}} 2 t d t=\left(\frac{x}{3}+\frac{y}{4}\right)^{2} \leq(x+y)^{2}-\frac{1}{4}\left(x+\frac{y}{4}\right)^{2} \\
& =\int_{0}^{x+y} 2 t d t-\int_{0}^{\psi\left(x+\frac{y}{4}\right)} 2 t d t \\
& =\int_{0}^{p(x, y)} w(r) d r-\int_{0}^{\psi(p(x, f y))} w(r) d r .
\end{aligned}
$$

Case 19. $(x, y) \in(1,+\infty) \times[0,1]$. Notice that

$$
\begin{aligned}
\int_{0}^{p(f x, f y)} w(r) d r & =\int_{0}^{\frac{x}{4}+\frac{y}{3}} 2 t d t=\left(\frac{x}{4}+\frac{y}{3}\right)^{2} \leq(x+y)^{2}-\frac{1}{4}\left(x+\frac{y}{3}\right)^{2} \\
& =\int_{0}^{x+y} 2 t d t-\int_{0}^{\psi\left(x+\frac{y}{3}\right)} 2 t d t \\
& =\int_{0}^{p(x, y)} w(r) d r-\int_{0}^{\psi(p(x, f y))} w(r) d r .
\end{aligned}
$$

Case 20. $(x, y) \in(1,+\infty) \times(1,+\infty)$. It follows that

$$
\begin{aligned}
\int_{0}^{p(f x, f y)} w(r) d r & =\int_{0}^{\frac{x+y}{4}} 2 t d t=\frac{1}{16}(x+y)^{2} \\
& \leq(x+y)^{2}-\frac{1}{4}\left(x+\frac{y}{4}\right)^{2} \\
& =\int_{0}^{x+y} 2 t d t-\int_{0}^{\psi\left(x+\frac{y}{4}\right)} 2 t d t \\
& =\int_{0}^{p(x, y)} w(r) d r-\int_{0}^{\psi(p(x, f y))} w(r) d r
\end{aligned}
$$

That is to say, (38) is true. Therefore, the conditions of Theorem 4 are fulfilled. Consequently, Theorem 4 means that $f$ possesses a unique fixed point in $X$. However, we cannot use Theorem 2.1 in [14] to show the existence of fixed points for the mapping $f$ in $X$. Or else, there is $(w, \psi) \in \Phi_{1}$ 
$\times \Phi_{4}$ with

$$
\begin{aligned}
0 & <\int_{0}^{\frac{1}{12}} w(r) d r=\limsup _{y \rightarrow 1^{+}} \int_{0}^{\frac{1}{3}-\frac{y}{4} \mid} w(r) d r \\
& =\limsup _{y \rightarrow 1^{+}} \int_{0}^{d(f 1, f y)} w(r) d r \\
& \leq \limsup _{y \rightarrow 1^{+}}\left(\int_{0}^{d(1, y)} w(r) d r-\int_{0}^{\psi(d(1, y))} w(r) d r\right) \\
& \leq \limsup _{y \rightarrow 1^{+}} \int_{0}^{d(1, y)} w(r) d r-\liminf _{y \rightarrow 1^{+}} \int_{0}^{\psi(d(1, y))} w(r) d r \\
& \leq 0-\int_{0}^{\psi(0)} w(r) d r=0,
\end{aligned}
$$

which is absurd.

Example 21. Let $X=R^{+}, d(x, y)=|x-y|$ and $p(x, y)=x+y$ $, \forall x, y \in X$. Let $f: X \rightarrow X, w$ and $\psi: R^{+} \rightarrow R^{+}$be defined by, respectively,

$$
f x=0, \forall x \in[0, \sqrt{3}], \frac{\sqrt{3}}{4} x, \forall x \in(\sqrt{3},+\infty),
$$

and

$$
w(r)=4 r, \quad \psi(r)=\frac{\sqrt{3}}{2} r, \forall r \in R^{+}
$$

Obviously, $p$ is a $\omega$-distance in $X$ and $(w, \psi) \in \Phi_{2} \times \Phi_{4}$. Let $x, y \in X$. To demonstrate (82), we consider four cases below:

Case 22. $(x, y) \in[0, \sqrt{3}] \times[0, \sqrt{3}]$. Evidently,

$$
\begin{aligned}
\int_{0}^{p(f x, f y)} w(r) d r & =0 \leq 2(x+y)^{2}-\frac{3}{2} y^{2} \\
& =\int_{0}^{p(x, y)} w(r) d r-\int_{0}^{\psi(p(f x, y))} w(r) d r .
\end{aligned}
$$

Case 23. $(x, y) \in[0, \sqrt{3}] \times(\sqrt{3},+\infty)$. Clearly,

$$
\begin{aligned}
\int_{0}^{p(f x, f y)} w(r) d r & =\int_{0}^{\frac{\sqrt{3}}{4} y} 4 r d r=\frac{3}{8} y^{2} \leq 2(x+y)^{2}-\frac{3}{2} y^{2} \\
& =\int_{0}^{x+y} 4 r d r-\int_{0}^{\psi(y)} 4 r d r \\
& =\int_{0}^{p(x, y)} w(r) d r-\int_{0}^{\psi(p(f x, y))} w(r) d r .
\end{aligned}
$$

Case 24. $(x, y) \in(\sqrt{3},+\infty) \times[0, \sqrt{3}]$. It is obvious that

$$
\begin{aligned}
\int_{0}^{p(f x, f y)} w(r) d r & =\int_{0}^{\frac{\sqrt{3}}{4} x} 4 r d r=\frac{3}{8} x^{2} \\
& \leq 2(x+y)^{2}-\frac{3}{2}\left(\frac{\sqrt{3}}{4} x+y\right)^{2} \\
& =\int_{0}^{x+y} 4 r d r-\int_{0}^{\psi\left(\frac{\sqrt{3}}{4} x+y\right)} 4 r d r \\
& =\int_{0}^{p(x, y)} w(r) d r-\int_{0}^{\psi(p(f x, y))} w(r) d r .
\end{aligned}
$$

Case 25. $(x, y) \in(\sqrt{3},+\infty) \times(\sqrt{3},+\infty)$. Clearly

$$
\begin{aligned}
\int_{0}^{p(f x, f y)} w(r) d r & =\int_{0}^{\frac{\sqrt{3}}{4}(x+y)} 4 r d r=\frac{3}{8}(x+y)^{2} \\
& \leq 2(x+y)^{2}-\frac{3}{2}\left(\frac{\sqrt{3}}{4} x+y\right)^{2} \\
& =\int_{0}^{x+y} 4 r d r-\int_{0}^{\psi\left(\frac{\sqrt{3}}{4} x+y\right)} 4 t d t \\
& =\int_{0}^{p(x, y)} w(r) d r-\int_{0}^{\psi(p(f x, y))} w(r) d r .
\end{aligned}
$$

In other words, (82) is true, and consequently, the conditions of Theorem 7 are fulfilled. Thus, Theorem 7 yields that $f$ possesses a unique fixed point in $X$. Next, we testify that Theorem 2.1 in [14] is unapplicable in ensuring the existence of fixed points for the mapping $f$ in $X$.

If there is $(w, \psi) \in \Phi_{1} \times \Phi_{4}$ satisfying the conditions of Theorem 2.1 in [14], we have

$$
0<\int_{0}^{\frac{3}{4}} w(r) d r=\limsup _{y \rightarrow \sqrt{3}^{+}} \int_{0}^{\left|0-\frac{\sqrt{3}}{4} y\right|} w(r) d r
$$

$$
\begin{aligned}
& =\limsup _{y \rightarrow \sqrt{3}^{+}} \int_{0}^{d(f \sqrt{3}, f y)} w(r) d r \\
& \leq \underset{y \rightarrow \sqrt{3}^{+}}{\limsup }\left(\int_{0}^{d(\sqrt{3}, y)} w(r) d r-\int_{0}^{\psi(d(\sqrt{3}, y))} w(r) d r\right) \\
& \leq \underset{y \rightarrow \sqrt[3]{3}^{+}}{\limsup } \int_{0}^{d(\sqrt{3}, y)} w(r) d r-\liminf _{y \rightarrow \sqrt{3}^{+}} \int_{0}^{\psi(d(\sqrt{3}, y))} w(r) d r \\
& \leq 0-\int_{0}^{\psi(0)} w(r) d r=0,
\end{aligned}
$$

which is ridiculous.

Example 26. Let $X=R^{+}, d(x, y)=|x-y|$ and $p(x, y)=y, \forall x$ ,$y \in \mathrm{X}$. Let $f: X \rightarrow X, w$ and $\psi: R^{+} \rightarrow R^{+}$be defined by, 
respectively,

$$
f x=0, \forall x \in[0,25], \frac{x}{5}, \forall x \in(25,+\infty)
$$

and

$$
w(r)=\frac{4}{5} r^{3}, \quad \psi(r)=5 \sqrt{r}, \forall r \in R^{+} .
$$

It is easy to see that $p$ is a $\omega$-distance in $X$ and $(w, \psi) \epsilon$ $\Phi_{1} \times \Phi_{4}$. Let $x, y \in X$. To prove (114), we have to consider two cases below:

Case 27. $(x, y) \in X \times[0,25]$. Apparently,

$$
\begin{aligned}
\int_{0}^{p(f x, f y)} w(r) d r=0 & \leq \frac{1}{5} y^{4}=\int_{0}^{p(x, y)} w(r) d r \\
& -\int_{0}^{\psi(p(f x, f y))} w(r) d r
\end{aligned}
$$

Case 28. $(x, y) \in X \times(25,+\infty)$. It is easy to demonstrate that

$$
\begin{aligned}
\int_{0}^{p(f x, f y)} w(r) d r & =\int_{0}^{\frac{y}{5}} \frac{4}{5} r^{3} d r=\frac{1}{5^{5}} y^{4} \leq \frac{1}{5} y^{4}-5 y^{2} \\
& =\int_{0}^{y} \frac{4}{5} r^{3} d r-\int_{0}^{\psi\left(\frac{y}{5}\right)} \frac{4}{5} r^{3} d r \\
& =\int_{0}^{p(x, y)} w(r) d r-\int_{0}^{\psi(p(f x, f y))} w(r) d r .
\end{aligned}
$$

Hence, (114) is true, and the conditions of Theorem 10 are satisfied. Thus, Theorem 10 guarantees that $f$ possesses a unique fixed point in $X$. Then, we certify that Theorem 2.1 in [14] is unfulfilled in showing the existence of fixed points for the mapping $f$ in $X$. Otherwise, there is $(w, \psi) \in$ $\Phi_{1} \times \Phi_{4}$ satisfying the conditions Theorem 2.1 in [14]. It means that

$$
\begin{aligned}
0 & <\int_{0}^{5} w(r) d r=\limsup _{y \rightarrow 25^{+}} \int_{0}^{\left|0-\frac{y}{5}\right|} w(r) d r \\
& =\limsup _{y \rightarrow 25^{+}} \int_{0}^{d(f 25, f y)} w(r) d r \\
& \leq \limsup _{y \rightarrow 25^{+}}\left(\int_{0}^{d(25, y)} w(r) d r-\int_{0}^{\psi(d(25, y))} w(r) d r\right) \\
& \leq \limsup _{y \rightarrow 25^{+}} \int_{0}^{d(25, y)} w(r) d r-\liminf _{y \rightarrow 25^{+}} \int_{0}^{\psi(d(25, y))} w(r) d r \\
& \leq 0-\int_{0}^{\psi(0)} w(r) d r=0,
\end{aligned}
$$

which is ridiculous.

\section{Applications}

In this section, we utilize Theorems 1 and 7 to investigate the solvability of the nonlinear Fredholm and Volterra integral equations below, respectively,

$$
\begin{gathered}
x(t)=h(t)+\int_{a}^{b} K(t, r, x(r)) d r, \forall t \in[a, b], \\
x(t)=h(t)+\int_{a}^{t} K(t, r, x(r)) d r, \forall t \in[a, b],
\end{gathered}
$$

where $a$ and $b$ are constants in $R$ with $a<b, h:[a, b] \rightarrow R$ and $K:[a, b]^{2} \times R \rightarrow R$ are given functions.

We assume that $C([a, b], R)$ denotes the Banach space of all continuous functions $x:[a, b] \rightarrow R$ with the norm $\|x\|=$ $\sup _{t \in[a, b]}|x(t)|$. Let $X=C([a, b], R)$ and

$$
d(x, y)=\sup _{r \in[a, b]}|x(r)-y(r)|, \forall x, y \in X
$$

Obviously, $(X, d)$ is a complete metric space. Define two mappings $T$ and $S$ as follows:

$$
\begin{gathered}
(T x)(t)=h(t)+\int_{a}^{b} K(t, r, x(r)) d r, \forall(t, x) \in[a, b] \times X \\
(S x)(t)=h(t)+\int_{a}^{t} K(t, r, x(r)) d r, \forall(t, x) \in[a, b] \times X
\end{gathered}
$$

Theorem 29. Let $h:[a, b] \rightarrow R$ and $K:[a, b]^{2} \times R \rightarrow R$ satisfy that

(a1) $h$ and $K$ are continuous;

(a2) there is $\psi \in \Phi_{4}$ with

$$
\begin{aligned}
& \left|\frac{h(t)}{b-a}+K(t, r, y(r))\right| \\
& \quad \leq \frac{\sup _{r \in[a, b]}|y(r)|-\psi\left(\sup _{r \in[a, b]}|y(r)|\right)}{b-a}, \forall(t, r, y) \in[a, b]^{2} \times X .
\end{aligned}
$$

Then, Eq. (142) possesses a unique solution in $X$.

Proof. Define two functions $w: R^{+} \rightarrow R^{+}$and $p: X \times X \rightarrow R^{+}$ by

$$
w(r)=\frac{1}{2}, \forall r \in R^{+}, p(x, y)=\sup _{t \in[a, b]}|y(t)|, \forall x, y \in X .
$$

Obviously, $p$ is a $\omega$-distance and $w \in \Phi_{1}$. It follows from (a1) and (145) that for arbitrary $x \in X, T x$ is continuous in $[a, b]$, which means that $T$ maps $X$ into itself. Taking account 
of (145) and (a2), we get that

$$
\begin{aligned}
\int_{0}^{|(T y)(t)|} w(r) d r & =\frac{1}{2}|(T y)(t)|=\frac{1}{2}\left|h(t)+\int_{a}^{b} K(t, r, y(r)) d r\right| \\
& \leq \frac{1}{2} \int_{a}^{b}\left|\frac{h(t)}{b-a}+K(t, r, y(r))\right| d r \\
& \leq \frac{1}{2} \int_{a}^{b} \frac{\sup _{r \in[a, b]}|y(r)|-\psi\left(\sup _{r \in[a, b]}|y(r)|\right)}{b-a} d r \\
& =\frac{1}{2} \int_{a}^{b} \frac{p(x, y)-\psi(p(x, y)) \mid}{b-a} d s \\
& =\int_{0}^{p(x, y)} w(r) d r-\int_{0}^{\psi(p(x, y))} w(r) d r, \forall(t, x, y) \\
& \in[a, b] \times X^{2} .
\end{aligned}
$$

It follows that

$$
\begin{aligned}
\int_{0}^{p(T x, T y)} w(r) d r= & \int_{0}^{\sup _{t \in[a, b]}|(T y)(t)|} w(r) d r \\
\leq & \int_{0}^{p(x, y)} w(r) d r-\int_{0}^{\psi(p(x, y))} w(r) d r \\
= & \int_{0}^{p(x, y)} w(r) d r \\
& -\int_{0}^{\psi(p(T x, y))} w(r) d r, \forall x, y \in X .
\end{aligned}
$$

That is, (2) and (82) hold. It follows from each of Theorems 1 and 7 that $T$ possesses a unique fixed point $x \in X$, that is, Eq. (142) has a unique solution $x \in X$.

We get, similar to the proof of Theorem 29, the following result and omit its proof.

Theorem 30. Let $h:[a, b] \rightarrow R$ and $K:[a, b]^{2} \times R \rightarrow R$ satisfy (a1) and (a2). Then, Eq. (143) possesses a unique solution in $X$.

\section{Conclusion}

By using $\omega$-distance, we prove several fixed point results for a few contractive mappings of integral type, some of which are used to investigate the existence and uniqueness of solutions for certain nonlinear Fredholm and Volterra integral equations, respectively. Four examples are provided to testify that our results extend or differ from some known results in the literature.

\section{Data Availability}

The data used to support the findings of this study are included within the article.

\section{Conflicts of Interest}

The authors declare that they have no competing interests.

\section{Authors' Contributions}

All authors contributed equally to the writing of this paper. All authors read and approved the final manuscript.

\section{Acknowledgments}

The authors thank the referees for their useful comments and suggestions. This work was supported by the National Natural Science Foundation of China (No. 41701616).

\section{References}

[1] A. Branciari, "A fixed point theorem for mappings satisfying a general contractive condition of integral type," International Journal of Mathematics and Mathematical Sciences, vol. 29, no. 9, 536 pages, 2002.

[2] J. Caristi, "Fixed point theorems for mappings satisfying inwardness conditions," Transactions of the American Mathematical Society, vol. 215, pp. 241-251, 1976.

[3] L. Ćirić, H. Lakzian, and V. Rakočević, "Fixed point theorems for $\mathrm{w}$-cone distance contraction mappings in tvs-cone metric spaces," Fixed Point Theory and Applications, vol. 2012, no. 1,2012

[4] I. Ekeland, "Nonconvex minimization problems," Bulletin of the American Mathematical Society, vol. 1, no. 3, pp. 443475, 1979.

[5] L. Guran, "Fixed points for multivalued operators with respect to a $\omega$-distance on metric spaces," Carpathian Journal of Mathematics, vol. 23, pp. 89-92, 2007.

[6] D. Ilić and V. Rakočević, "Common fixed points for maps on metric space with w-distance," Applied Mathematics and Computation, vol. 199, no. 2, pp. 599-610, 2008.

[7] M. Imdad and F. Rouzkard, "Fixed point theorems in ordered metric spaces via w-distances," Fixed Point Theory and Applications, vol. 2012, no. 1, 2012.

[8] O. Kada, T. Suzuki, and W. Takahashi, "Nonconvex minimization theorems and fixed point theorems in complete metric spaces," Mathematica Japonicae, vol. 44, pp. 381-391, 1996.

[9] S. Kaneko, W. Takahashi, C. F. Wen, and J. C. Yao, "Existence theorems for single-valued and set-valued mappings with wdistances in metric spaces," Fixed Point Theory and Applications, vol. 2016, no. 1, 2016.

[10] H. Lakzian, H. Aydi, and B. E. Rhoades, "Fixed points for $(w$ $, \psi, p)$-weakly contractive mappings in metric spaces with $\omega$ -distance," Applied Mathematics and Computation, vol. 219, pp. 6777-6782, 2013.

[11] Z. Liu, M. He, X. Liu, and L. Zhao, "Common fixed point theorems for four mappings satisfying contractive inequalities of integral type," Nonlinear Functional Analysis and Applications, vol. 23, pp. 473-501, 2018.

[12] Z. Liu, X. Li, S. Kang, and S. Cho, "Fixed point theorems for mappings satisfying contractive conditions of integral type and applications," Fixed Point Theory and Applications, vol. 2011, no. 1, 2011.

[13] Z. Liu, Y. Wang, S. M. Kang, and Y. C. Kwun, "Some fixed point theorems for contractive mappings of integral type," 
The Journal of Nonlinear Sciences and Applications, vol. 10, no. 7, pp. 3566-3580, 2017.

[14] Z. Liu, H. Wu, J. Ume, and S. Kang, "Some fixed point theorems for mappings satisfying contractive conditions of integral type," Fixed Point Theory and Applications, vol. 2014, no. 1, 2014.

[15] B. E. Rhoades, "Some theorems on weakly contractive maps," Nonlinear Analysis: Theory, Methods \& Applications, vol. 47, no. 4, pp. 2683-2693, 2001.

[16] W. Takahashi, "Existence theorems generalizing fixed point theorems for multivalued mappings," in Fixed Point Theory and Applications, M. A. Théra and J. B. Baillon, Eds., vol. 252 of Pitman Research Notes in Mathematics Series, 406 pages, 1991.

[17] F. Zhang, H. Wang, S. Wu, and L. Zhao, "Fixed-point theorems for-admissible mappings with -distance and applications to nonlinear integral equations," Mathematical Problems in Engineering, vol. 2020, Article ID 2804802, 7 pages, 2020. 